\title{
Projected climate change impact on Baltic Sea cyanobacteria
}

\section{Climate change impact on cyanobacteria}

\author{
Inga Hense • H. E. Markus Meier • Sebastian Sonntag
}

Received: 28 April 2012 / Accepted: 17 January 2013 / Published online: 19 February 2013

(C) The Author(s) 2013. This article is published with open access at Springerlink.com

\begin{abstract}
Compared to other phytoplankton groups, nitrogen-fixing cyanobacteria generally prefer high water temperatures for growth and are therefore expected to benefit from global warming. We use a coupled biological-physical model with an advanced cyanobacteria life cycle model to compare the abundance of cyanobacteria in the Baltic Sea during two different time periods (1969-1998; 2069-2098). For the latter, we find prolonged growth and a more than twofold increase in the climatologically (30 years) averaged cyanobacteria biomass and nitrogen fixation. Additional sensitivity experiments indicate that the biological-physical feedback mechanism through light absorption becomes more important with global warming. In general, we find a nonlinear response of cyanobacteria to changes in the atmospheric forcing fields as a result of life-cycle related feedback mechanisms. Overall, the sensitivity of the cyanobacteria-driven system suggests that biological-physical and life-cycle related feedback mechanisms are important and must therefore be included in future projection studies.
\end{abstract}

Keywords Cyanobacteria $\cdot$ Climate change $\cdot$ Life cycle $\cdot \mathrm{N}_{2}$-fixation . Phytoplankton • Biological-physical feedback mechanisms

\section{Introduction}

Cyanobacteria in aquatic systems are generally assumed to benefit from global warming (Paerl and Huisman 2008, 2009). Current sea surface temperatures (SST) in many regions are below their growth optimum $\left(\sim 25^{\circ} \mathrm{C}\right.$, Robarts and Zohary 1987$)$,

I. Hense ( $\varangle)$. S. Sonntag

IHF, KlimaCampus, CEN, University of Hamburg, Hamburg, Germany

e-mail: inga.hense@uni-hamburg.de

H. E. Markus Meier

SMHI, Norrköping, Sweden 
so that a rise in SST will lead to improved conditions for cyanobacteria growth. An increasing number of large blooms of cyanobacteria has been recorded in freshwater, brackish and marine oligotrophic environments in recent years. In many cases $\mathrm{N}_{2}$-fixing cyanobacteria species dominate, bringing new nitrogen into the system. They are responsible for higher export production (Karl et al. 1997) and eutrophication (Rolff et al. 2007).

Cyanobacterial bloom formation is stimulated by several positive feedback mechanisms (Hense 2007; Johnk et al. 2008; Paerl and Huisman 2008; Sonntag and Hense 2011). A prominent one is through light absorption leading to near surface warming and therefore enhanced growth (the surface accumulation-light absorptiontemperature feedback, see, e.g., Kahru et al. 1993). In shallow waters there is a similarly important feedback mechanism. It is linked to the life cycle of cyanobacteria consisting of pelagic growing and benthic resting stages. The higher the abundance of vegetative cells, the more resting cells are produced. This leads to enhanced germination, a higher "inoculum" and thus to an increase in the abundance of vegetative cells (Hense 2007). The transitions between these life cycle stages mark the beginning and end of the bloom season. Resolving the life cycle processes in models has significantly improved the representation of the seasonal cycle and large year-to-year fluctuations of Baltic Sea $\mathrm{N}_{2}$-fixing cyanobacteria (Hense and Burchard 2010).

In the central Baltic Sea, widespread surface scums of $\mathrm{N}_{2}$-fixing cyanobacteria have been frequently observed. They reach maximum abundance in July and cover areas of up to $200,000 \mathrm{~km}^{2}$ (Kahru et al. 2007). The dominant species in these surface mats is the positively buoyant, toxin-producing Nodularia spumigena which can form benthic resting stages (Suikkanen et al. 2010). The observed increase in the occurrence and spatial extent of blooms in at least the past 20 years (Kahru et al. 1994; Suikkanen et al. 2007) raises the question whether this trend is likely to continue. Due to their significant impacts on the ecosystem, biogeochemical cycling, and human society, quantitative estimates of future cyanobacteria bloom magnitude and duration are of interest.

In recent studies, projections to investigate future ecosystem and biogeochemical changes in the Baltic Sea have been carried out based on climate model runs (Neumann 2010; Meier et al. 2011b, c). Depending on the specific climate and nutrient load scenarios used, the model results are quite diverse: Future cyanobacteria concentrations may be increased or decreased and the growth and $\mathrm{N}_{2}$-fixation period of cyanobacteria remains similar or is somewhat prolonged. A common feature of these studies is that the life cycle of cyanobacteria and related feedback mechanisms as identified in Hense (2007) are not taken into account.

State-of-the-art climate models generate a dynamically consistent trajectory of the system's evolution with reliable statistics (mean, variance) over a period of 30 years or longer. They do not, however, reproduce the specific succession of years, the "chronology", of climate variables for the control/hindcast period. Thus, for future ecosystem projections using the output of climate model runs, it is implicitly assumed that the chronology has no effect on ecosystem dynamics. This may be true for some processes, but not if the organisms' life cycle leads to nonlinearities and multi-year system memory.

To investigate future changes in cyanobacteria abundance, to address the uncertainty concerning the impact of the succession of cold and warm years as well as 
the sensitivity of the system to atmospheric forcing fields and feedback mechanisms, we have conducted a number of simulations with a Baltic Sea ecosystem model that includes an advanced cyanobacteria life cycle model, two phytoplankton groups (diatoms and flagellates) and other biogeochemical variables (Hense and Burchard 2010). We study the changes in the cyanobacteria concentrations for a climatological (30-year) period at the end of this century (2069-2098) compared to a 30-year period at the end of the past century (1969-1998). In a number of numerical experiments we analyze the robustness of the results and the sensitivity of the cyanobacteria driven ecosystem.

\section{Model description}

\subsection{Model setup}

We use the same modelling system as in Hense and Burchard (2010), which combines an advanced cyanobacteria life cycle model with an ecosystem model in a physical water column model. The cyanobacteria life cycle model CLC (Hense and Beckmann 2006) considers four different life cycle stages that are characterized by different internal nitrogen and energy quotas. The vegetative stage, during which dissolved inorganic nitrogen is taken up, is followed by a nitrogen fixing stage under DIN limitation. These both vegetative life cycle stages are positively buoyant. Energy limitation leads to a transformation into the resting stage (akinetes), during which the cells sink to the bottom and "mature" (by refilling their internal nitrogen quota). The life cycle is closed by rising recruiting cells after maturation. All life and life cycle processes, i.e. growth, nitrogen fixation, nutrient uptake and maturation depend directly or indirectly on temperature and energy/light.

The Baltic Sea ecosystem model ERGOM (Neumann 2000) provides the biogeochemical environment (diatoms, flagellates, zooplankton, nitrate, ammonium, phosphorus, detritus and oxygen). ERGOM's simpler cyanobacteria formulation was replaced by CLC. Coupled to the physical water column model GOTM (Umlauf et al. 2005), the model system has been applied to the Eastern Gotland Basin, Baltic Sea $\left(57.3^{\circ} \mathrm{N}, 20^{\circ} \mathrm{E}\right)$ (see Hense and Burchard 2010). The results have been analyzed for a 35 year period and evaluated against observations. Compared with other model formulations for cyanobacteria, the ERGOM-CLC results stand out with the most realistic seasonal cycle. The model is able to capture high year-toyear fluctuations; and the $\mathrm{N}_{2}$-fixation rates are within the range of observed values (Hense and Burchard 2010).

For the studies reported here, the only difference in the model configuration is the use of a climatological salinity profile for the hindcast period and a profile with reduced salinities ( $\sim 2$ salinity units at the surface and 1.7 at the bottom) for the projection period. A spin-up phase of 10 years is applied and all experiments start with the same initial conditions. The model is forced by the 6-hourly atmospheric variables $(2 \mathrm{~m}$ air and dew point temperature, air pressure, $10 \mathrm{~m}$ zonal- and meridional wind velocities, cloud cover and precipitation). They stem from either the ECMWF ERA40 reanalysis (Uppala et al. 2005) for the period 1969-1998 or from the projection data set (2069-2098). 
2.2 Forcing fields for the projection experiments

It is well known that the results of climate models are always deficient in some respects, illustrated by deviations of statistical quantities for the control/hindcast period: in particular decadal and year-to-year variability may differ significantly from those seen in observations. The quality of a simulation of the pelagic ecosystem in permanently or seasonally warm and nitrogen depleted surface waters, however, depends crucially on realistic heat and momentum data, due to the high temperature sensitivity of $\mathrm{N}_{2}$-fixing cyanobacteria.

We have therefore generated atmospheric forcing fields for the projections using ECMWF ERA40-reanalyses (hereafter ERA40) and our analyses of the RCAO model run in a specific way (see Appendix A, Fig. 6): Starting from the atmospheric forcing fields of the global HadCM3-A1B-scenario (Gordon et al. 2000), a long-term (1958-2099) downscaling climate model run has been carried out with the regional Baltic Sea coupled atmosphere ocean model RCAO (Döscher et al. 2002; Meier et al. 2011a). The obtained atmospheric data were then analyzed for the 30-year control (1969-1998) and projection (2069-2098) periods. Compared to the control period, the projection period has mean air and dew point temperatures increased by $3.38^{\circ} \mathrm{C}$ and $3.45^{\circ} \mathrm{C}$, respectively, slightly decreased mean wind velocities (by $3.2 \%$ ) and only minor changes in air pressure and cloud cover. While the amplitude of the fluctuations increases for precipitation, cloud cover and air pressure, it decreases for all other variables (see Appendix A, Table 3).

The results of the control period were also compared to the ERA40 reanalysis data (see Appendix A, Table 3). We found differences in both the mean and the variances of atmospheric variables between ERA40 and the control period of the RCAO (see Appendix A, Table 3).

In order to investigate the effects of a warmer climate on the succession of blooms, we use the fluctuations of the ERA40 period also as the basis for the future scenario. Assuming that the change in climatological mean and mean amplitude of the fluctuations of all variables $(x)$ in the downscaling experiment is reliable, we constructed the forcing data set for the water column model by setting the climatological mean to

$$
\bar{x}_{\mathrm{PROJ}}=\bar{x}_{\mathrm{ERA} 40}+\bar{x}_{\mathrm{HADCM} 21}-\bar{x}_{\mathrm{HADCM} 20}
$$

and the absolute value of the fluctuations $(a v f)$ to

$$
\operatorname{avf}_{\text {PROJ }}=\operatorname{avf}_{\text {ERA } 40} \cdot \frac{\operatorname{avf}_{\text {HADCM } 21}}{\operatorname{avf}_{\text {HADCM } 20}}
$$

with

$$
\operatorname{avf}=\frac{1}{n} \sum_{i=1}^{n}\left|x_{i}-\bar{x}\right|
$$

This way we take into account changes of the mean state and magnitude of the fluctuations of the variables: By applying the so-called delta change approach (e.g. Meier et al. 2011b), we have replaced the mean over the hindcast period of all atmospheric variables from ERA40 by the mean of the projection period from RCAO to construct a suitable atmospheric forcing data set for the projection period. In addition, we consider the changes in the magnitude of the fluctuations of the 
atmospheric variables for the projections: the fluctuations in ERA40 are multiplied by the ratio of the absolute value of the fluctuations (hereafter: avf) between the control and the projection period of RCAO. Hence, the interannual variability, that is the succession of cold and warm years (positive and negative anomalies), remains the same as for the hindcast atmospheric forcing field of ERA40. This has been done to facilitate the interpretation of the results, primarily of the effects due to the cyanobacteria's life cycle.

In addition to modifications in the forcing fields, ocean salinity has been changed for the projection period. We have analyzed the RCAO ocean data set at the specific location for the control and projection period. They show a decrease in salinity for the projection period by about 2 salinity units at the surface and 1.7 at the bottom in $250 \mathrm{~m}$ depth due to enhanced river runoff. We have taken the relative changes in the salinity profile into account for salinity restoring in the water column.

\subsection{Scenario runs}

The main focus of this study is to compare the results of the coupled biologicalphysical ocean model runs for the two periods with different forcing data sets (Table 1):

- ERA40: 30 year time slice 1969-1998 with ERA40-forcing

- PROJ: 30 year time slice 2069-2098 with the newly calculated means of the projections in all atmospheric variables but using ERA40-fluctuations multiplied by the $a v f$-ratio and with restoring to reduced (climatological) salinity profiles

In order to further analyze the changes of cyanobacteria between the hindcast and the projection period, we have conducted several sensitivity studies (Table 1). Specifically, we investigate the effect of (i) interannual variability, (ii) the biologicalphysical feedback mechanism through light absorption, and (iii) changes in the atmospheric variables.

The rationale behind the first experiment is that the future succession of cold and warm years is unknown. This uncertainty can be addressed by only changing

Table 1 Overview of the reference and sensitivity model runs that are performed

\begin{tabular}{|c|c|c|}
\hline Scenario & Forcing & Description \\
\hline ERA40 & ERA40 & Hindcast \\
\hline PROJ & PROJ & Projection \\
\hline ERA40-MOD1 & ERA40* & Randomly changed order of the individual years \\
\hline PROJ-MOD1 & PROJ* & Ditto \\
\hline ERA40-MOD2 & ERA40* & $\begin{array}{l}\text { Individual years arranged according to their maximum } \\
\text { summer temperature (increasing order) }\end{array}$ \\
\hline PROJ-MOD2 & PROJ* & Ditto \\
\hline ERA40-NFB & ERA40* & Temperature changes through light absorption are neglected \\
\hline PROJ-NFB & PROJ* & Ditto \\
\hline PROJ-TEMP-DEW & PROJ* & $\begin{array}{l}\text { Values for both air and dew point temperature are the } \\
\text { original ERA40 values from the period 1969-1998 }\end{array}$ \\
\hline PROJ-WIND & PROJ* & $\begin{array}{l}\text { Values for wind speed are the original ERA } 40 \text { values } \\
\text { from the period 1969-1998 }\end{array}$ \\
\hline
\end{tabular}

The sensitivity model runs with modified forcing fields are marked by * 
the sequential arrangement of years for the hindcast and projection period and quantifying the effects on the cyanobacteria concentrations (-MOD). The means and the variances of the atmospheric variables remain unchanged.

Since cyanobacteria blooms affect the light absorption and therefore depthdependent warming in the water column significantly, any change in cyanobacteria abundance will affect temperature and in turn growth of cyanobacteria. Considering or omitting the light absorption feedback for both time periods allows to quantify these effects (-NFB).

The third set of sensitivity experiments is necessary to determine which of the atmospheric variable change (temperature/dew point or wind) has the strongest impact on cyanobacteria concentrations (-TEMP-DEW, -WIND).

\section{Results}

\subsection{Past and projected cyanobacterial dynamics}

The simulation results of the hindcast (1969-1998) time slice experiment ERA40 and the projection (2069-2098) time slice experiment PROJ show significant differences with respect to SST and the surface concentrations of nitrogen-fixing cells. As expected, the SST in the climatological seasonal cycle is higher by about $3{ }^{\circ} \mathrm{C}$ in the 21st century time slice (Fig. 1). Not surprisingly, cyanobacteria concentrations are increased in PROJ. In the 3-month period from beginning of June to end of August cyanobacteria concentrations are on average 2.3 times higher.

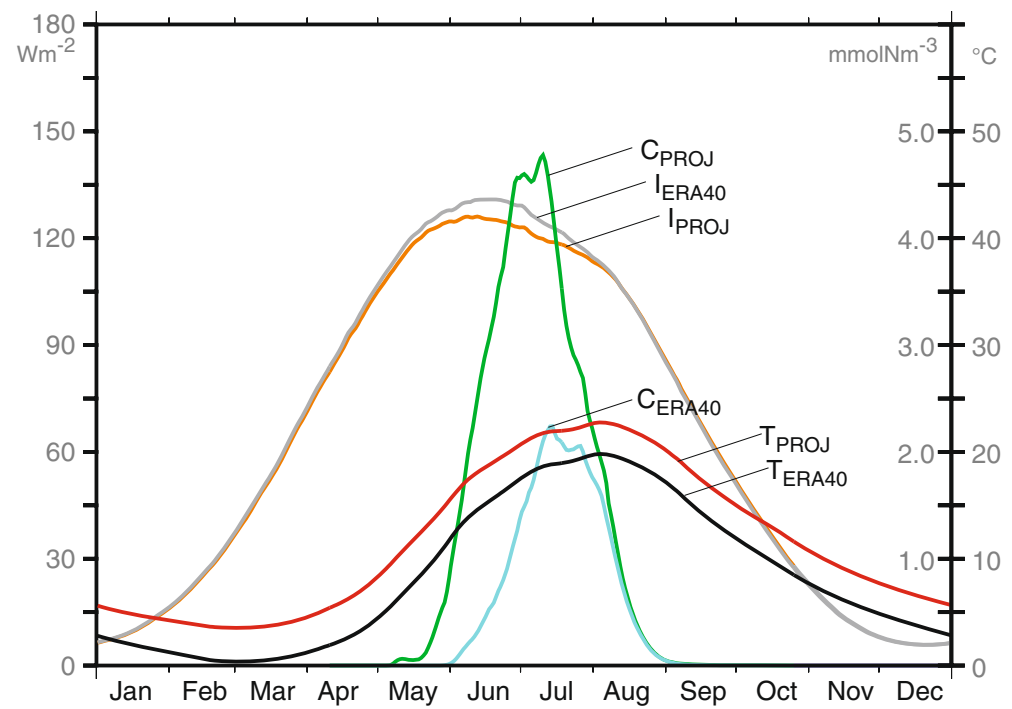

Fig. 1 Climatological seasonal cycle of sea surface temperature $\mathbf{T}$ (15-days running mean), surface photosynthetic irradiation I (30-days running mean) and surface cyanobacteria concentrations $\mathbf{C}$ in the hindcast period (ERA40: 1969-1998) and projected time period (PROJ: 2069-2098) 
To further illustrate the changes between ERA40 and PROJ, we have introduced two criteria for potential cyanobacteria growth. The first one is related to the temperature window in which cyanobacteria growth can take place (above the threshold of $12{ }^{\circ} \mathrm{C}$ ) and can be seen as an indicator for the duration of the potential growth period. Compared to ERA40, we find a prolonged duration of the potential growth period in PROJ (Fig. 2, left), because the temperature threshold for growth of $12{ }^{\circ} \mathrm{C}$ is exceeded earlier in the year and SST stays above this value longer. Indeed, the beginning of the bloom is about 10 days earlier and marked by a steeper increase of the $\mathrm{N}_{2}$-fixing cells (Fig. 1). However, the end of the bloom coincides for both time slices. This can be explained by energy limitation due to decreasing solar radiation which terminates the growth of the $\mathrm{N}_{2}$-fixing life cycle stage and initiates the formation of resting cells (akinetes) (see Hense and Beckmann 2006). The slightly lower solar radiation in PROJ (Fig. 1) has no noticeable impact on cyanobacteria growth.

The second criterion for potential cyanobacteria growth is a measure for the magnitude of the bloom and refers to the period with higher temperatures $\left(>17^{\circ} \mathrm{C}\right)$ where substantial growth occurs (Fig. 2, right). The differences between PROJ and ERA40 are even more pronounced for this period. In contrast to ERA40, relative high SSTs occur for more than two months each year without interruptions in PROJ (Fig. 2, right). This is reflected by the generally higher summer concentrations of cyanobacteria (Fig. 3). The year '87, for instance, is characterized by a very short period of higher temperatures and low cyanobacteria concentrations in ERA40 but a significantly extended period of higher temperatures and 4 times higher cyanobacteria concentrations in PROJ (Fig. 3).

Despite very similar forcing fields (only the mean and amplitude of the fluctuations differ slightly), the succession of blooms is quite different in PROJ and ERA40 (Fig. 3). In the projection, the formation of a "seed bank" is supported as
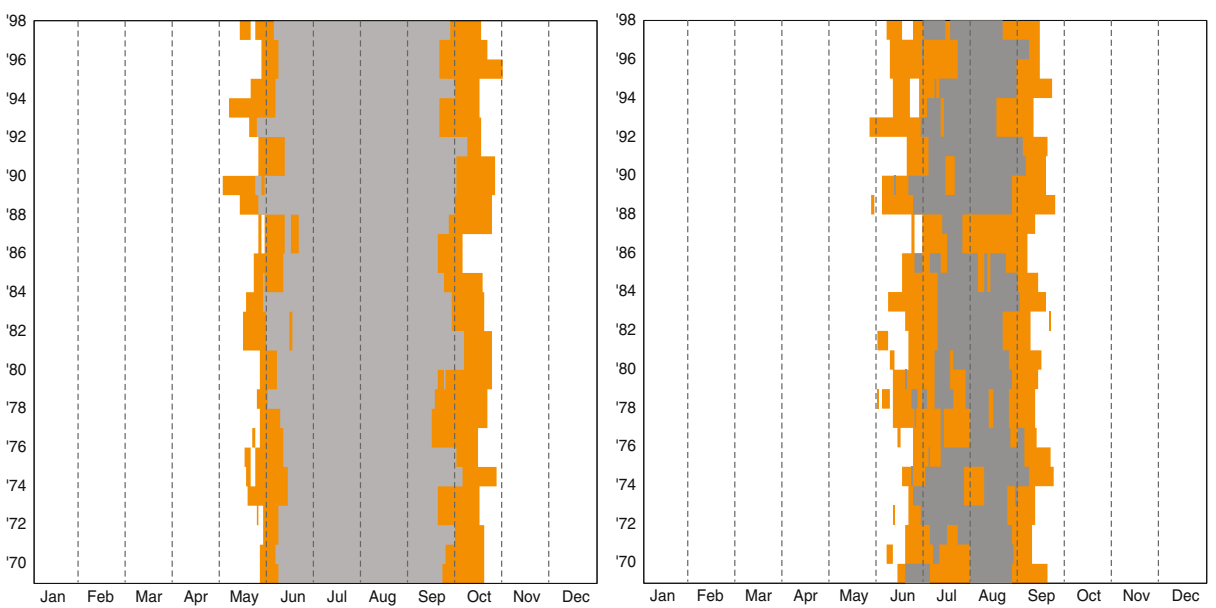

Fig. 2 Temperature windows for potential growth within the seasonal cycle for the hindcast (ERA40: grey, overlayed) and projected (PROJ: orange) time period, assuming that growth can take place only above temperatures of $12^{\circ} \mathrm{C}$ (left) and is significant at temperatures above $17^{\circ} \mathrm{C}$ (right) 


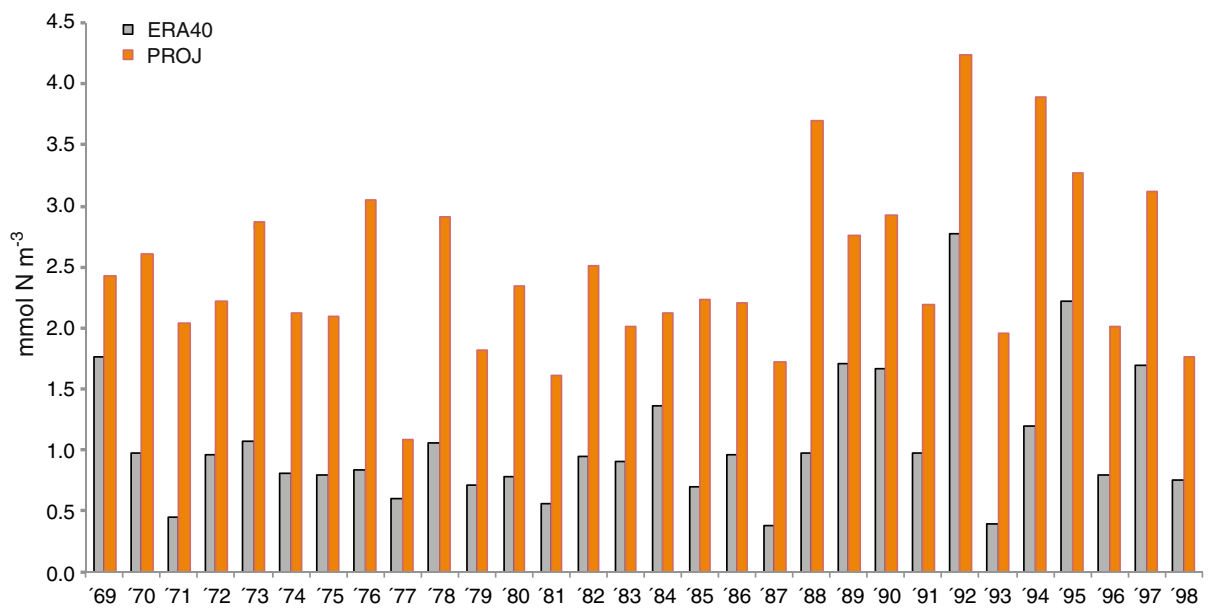

Fig. 3 Time series of surface cyanobacteria concentrations averaged over the 3-month summer period (Jun-Aug) in the hindcast and projection period

a result of higher temperatures and a prolonged growth period. The concentration of resting cells in the bottom layers is two times higher in PROJ than in ERA40 (Table 2). The effect is twofold: First, generally higher initial concentrations of resting and germinating cells in the beginning of the growth period stimulate bloom formation (see Hense 2007). Second, years in which the temperature is relatively low and growth conditions are unfavorable have a smaller effect on cyanobacteria concentrations in the following years. In ERA40 relatively cold summer temperatures in certain years lead to perturbations of the build up of a significant amount of resting cells, because there is hardly any flux of resting cells to the sediment in these years. As a result, bloom formation is affected also in the following years,

Table 2 30-year climatological means of annually averaged SST, bloom-time SST (3 month: JunAug), annually integrated surface cyanobacteria concentrations, annually and vertically integrated nitrogen fixation rates and annually and vertically averaged biomass of resting cells

\begin{tabular}{lcllll}
\hline simulation & $\begin{array}{c}\text { Annual } \\
\text { mean } \\
\mathrm{SST}\left({ }^{\circ} \mathrm{C}\right)\end{array}$ & $\begin{array}{l}\text { Bloom } \\
\text { period } \\
\mathrm{SST}\left({ }^{\circ} \mathrm{C}\right)\end{array}$ & $\begin{array}{l}\mathrm{N}_{2} \text {-fixing cells } \\
\left(\mathrm{mmol} \mathrm{N} \mathrm{m}^{-3}\right)\end{array}$ & $\begin{array}{l}\mathrm{N}_{2} \text {-fixation } \\
\left(\mathrm{mmol} \mathrm{N} \mathrm{m}^{-2} \mathrm{y}^{-1}\right)\end{array}$ & $\begin{array}{l}\text { Resting cells } \\
\left(\mathrm{mmol} \mathrm{N} \mathrm{m}^{-3}\right)\end{array}$ \\
\hline ERA40 & 8.43 & 17.63 & 98.06 & 117.6 & 4.45 \\
PROJ & 11.61 & 20.82 & 232.6 & 275.9 & 8.81 \\
ERA40-MOD1 & 8.43 & 17.64 & 103.1 & 121.7 & 5.16 \\
PROJ-MOD1 & 11.61 & 20.82 & 232.7 & 276.7 & 9.21 \\
ERA40-MOD2 & 8.43 & 17.64 & 104.0 & 122.4 & 4.50 \\
PROJ-MOD2 & 11.60 & 20.82 & 230.9 & 274.8 & 8.77 \\
ERA40-NFB & 8.43 & 17.42 & 94.0 & 113.7 & 4.18 \\
PROJ-NFB & 11.61 & 20.57 & 220.4 & 266.3 & 8.12 \\
PROJ-WIND & 11.59 & 20.83 & 230.5 & 275.0 & 8.77 \\
PROJ-TEMP-DEW & 8.42 & 17.57 & 92.76 & 111.4 & 4.25 \\
\hline
\end{tabular}


since the growth rate for $\mathrm{N}_{2}$-fixing cells is low $\left(0.23 \mathrm{~d}^{-1}\right)$ even under optimal conditions. Therefore, cold years have much longer lasting effects in the hindcast period.

Significant differences in the concentrations and succession of blooms in ERA40 and PROJ are reflected in the histograms of summer cyanobacteria concentrations (Fig. 4). We find a shift towards high concentrations in the projections (Fig. 4). In addition, the histogram is slightly skewed to the left, i.e. to lower concentrations in ERA40, but more symmetric in PROJ. Typical bloom concentrations in ERA40 have an amplitude which occurs only once in PROJ.

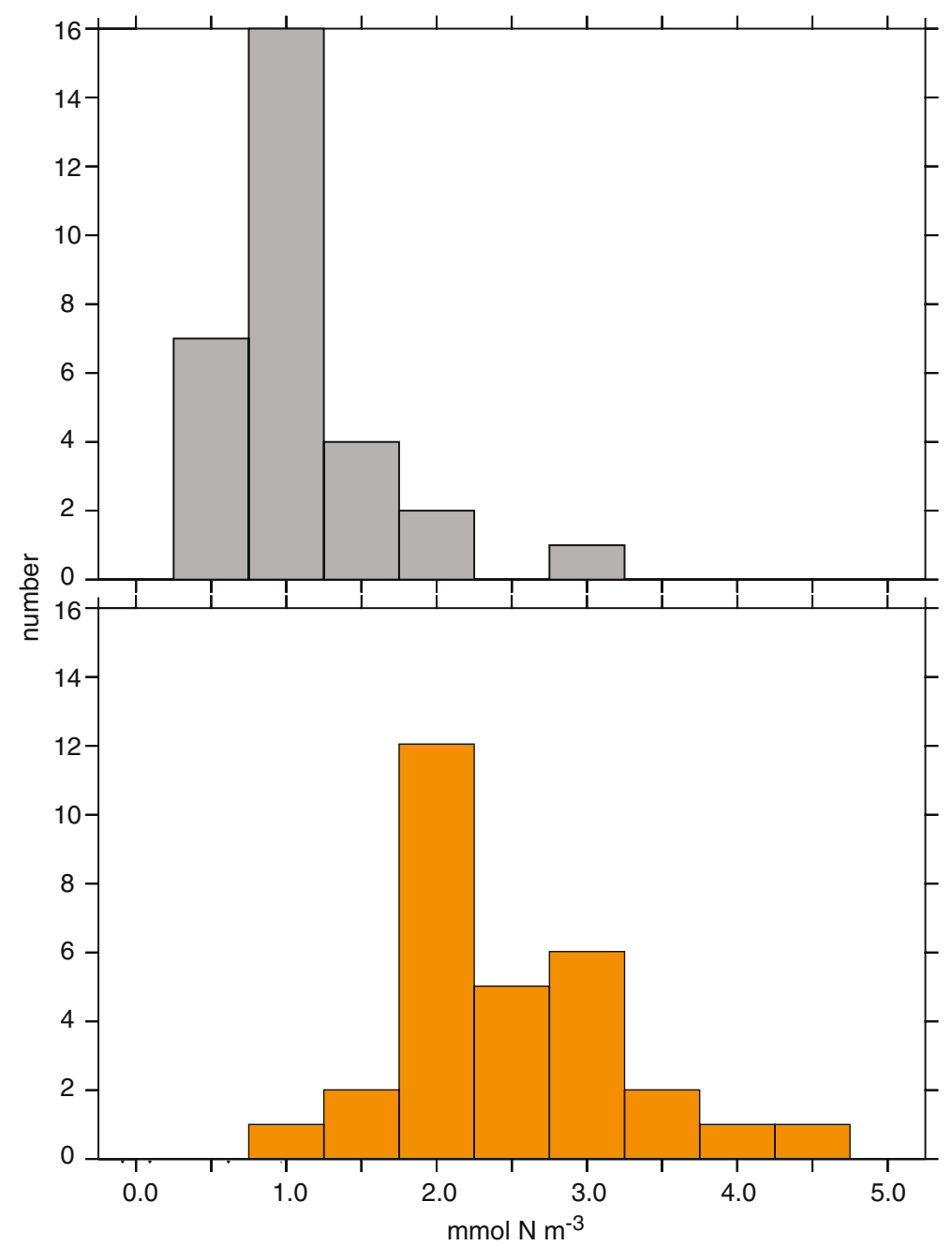

Fig. 4 Histogram of the cyanobacteria bloom concentrations for the hindcast time period (19691998, ERA40, upper panel) and projected time period (2069-2098, PROJ, lower panel). The surface cyanobacteria concentrations are averaged over three months in the summer period (1 Jun-31 Aug) and split into bins with an increment of $0.5 \mathrm{mmol} \mathrm{N} \mathrm{m}^{-3}$ 
3.2 Relative sensitivity of cyanobacteria to atmospheric forcing and light absorption feedback

The succession of cyanobacteria blooms is different in hindcast and projection, despite the same sequence of cold and warm years in the forcing fields. This is the result of life-cycle related feedback mechanisms. To investigate the nonlinearity, we have performed several sensitivity experiments.

First, we elucidate the effect of the interannually varying forcing on the climatological seasonal cycle of cyanobacteria. In two sensitivity model runs, the order of years in the forcing fields in both hindcast and projections has been changed (Fig. 5, left), i.e. the climatological seasonal cycle in the atmospheric forcing fields remains the same. Nevertheless, pronounced differences between the different model runs occur. In hindcast the succession of years has an impact on the climatological seasonal cycle of cyanobacteria. Cyanobacterial concentrations in summer are higher by roughly $10 \%$ in ERA40-MOD1 and ERA40-MOD2. Incidentally, due to the specific random choice of years in ERA40-MOD1, relatively high temperatures occur in the first ten years of the model run. The period in the beginning of the integration period which favors growth is therefore longer in ERA40-MOD1 than in ERA40. Enhanced growth of cyanobacteria and the build up of a significant amount of resting cells can take place (Table 2), while in ERA40 relatively cold years (in the second and sixth year of the model integration) perturb the formation of a larger standing stock of akinetes (Table 2). Later on in the model integration of ERA40-MOD1 the importance of these cold snaps decreases, because a significant amount of inoculum already exists. In ERA40-MOD2, the standing stock of resting cells increases with time over the whole integration period and explains the $10-20 \%$ higher summer concentrations of cyanobacteria in the end of the model integration period compared to ERA40. The differences between PROJ and the two sensitivity runs PROJ-MOD1 and PROJ-MOD2 in the climatological seasonal cycle are negligible (Table 2). Since the conditions for cyanobacteria bloom formation and production of resting stages are still good even in the relatively cold years, the inoculum each year is high enough to support growth.

Second, we investigate the relative importance of the biological-physical feedback through light absorption in hindcast and projections (Fig. 5, center). While in hindcast the differences in the seasonal cycle of cyanobacteria between ERA40 and
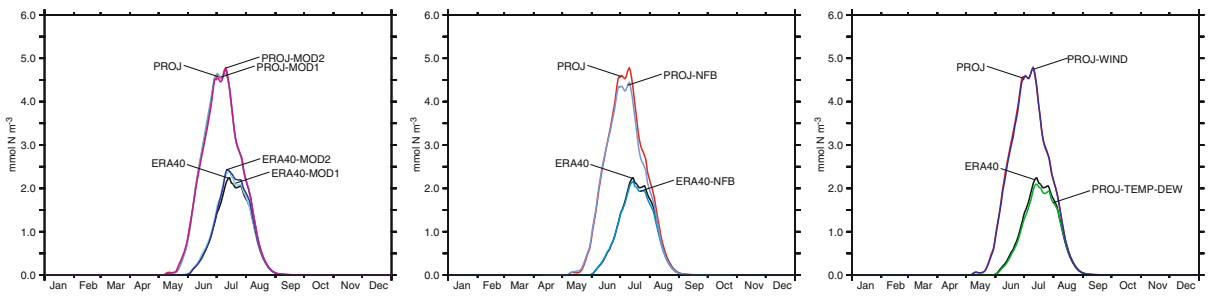

Fig. 5 Climatological seasonal cycle of the surface cyanobacteria concentrations in hindcast (ERA40), projections (PROJ) and the sensitivity experiments, where the order of years in the atmospheric forcing fields have been changed (left:-MOD1, -MOD2), the feedback through light absorption has been omitted (center: -NFB) and where the sensitivity to projected changes in the atmospheric forcing fields have been investigated (right: PROJ-TEMP-DEW, PROJ-WIND) 
ERA40-NFB are minor ( $2.5 \%$ lower summer concentrations), the summer concentrations are significantly lower in PROJ-NFB compared to PROJ. Once the overall growth conditions are favorable, light absorption of the buoyant cyanobacteria is increased leading to cyanobacteria induced heating at the surface and a positive net effect for growth.

Third, in order to quantify the relative impact of the projected changes in the individual atmospheric variables on cyanobacteria, two further sensitivity experiments are conducted: the effects of changes in atmospheric temperature and wind speed on cyanobacteria concentrations and nitrogen fixation are investigated in PROJ-TEMPDEW and PROJ-WIND (Fig. 5, right, Table 2). Additional model experiments where the effect of changes in cloud cover, precipitation and air pressure as well as in ocean salinity have been studied, show only negligible impacts on the cyanobacteria concentrations and are not presented.

The predominant effect of the changes in cyanobacteria abundance in PROJ compared to ERA40 is due to the combined action of air and dew point temperatures. The seasonal cycle of the cyanobacteria in PROJ-TEMP-DEW is close to ERA40 and also the magnitude of the bloom is the same. Changes in the wind speed (PROJ-WIND), however, have only a slight impact on the annual mean sea surface temperature and cyanobacteria concentrations (Table 2). The deviation from the summer maximum biomass is about $1 \%$, but in individual years the changes can be as high as $10 \%$. Nevertheless, the differences between PROJ-WIND and PROJ are in the same order of magnitude as the differences between PROJ and PROJ-MOD1 or PROJ and PROJ-MOD2, although the climatologies in the atmospheric variables of the latter runs are the same.

\section{Discussion}

In response to observational studies indicating an increase of cyanobacteria concentrations in aquatic systems in recent years (see, e.g., Paerl and Huisman 2009; Wiedner et al. 2007; Wagner and Adrian 2004; Kosten et al. 2012) a number of climate change projection studies on the future development of cyanobacteria blooms have been conducted for freshwater (Elliott 2012), brackish (Neumann 2010; Meier et al. 2011b) and marine systems (Boyd and Doney 2002). In these studies the effects on cyanobacteria of an increase in temperature or additional changes in nutrient discharges are examined. The results do not provide a unified picture. For the Baltic Sea, an earlier start of the cyanobacteria bloom but lower concentrations are projected by Neumann (2010) leading to similar mean nitrogen fixation rates in hindcast and projections. Meier et al. (2011b) show a wide range of responses of Baltic Sea cyanobacteria depending on the climate change and nutrient supply change scenarios. None of the previous model projections, however, has taken into account the feedbacks related to the cyanobacteria life cycle and the biologicalphysical feedback mechanism through light absorption.

In the present study we include these feedbacks in the model and show that both aspects are crucial. The alternation between growing (pelagic) and resting (benthic) stages of cyanobacteria has to be included to adequately describe the seasonal and interannual variability of cyanobacteria in hindcasts as shown by Hense and Burchard (2010). Compared to the hindcast period our projection suggests a 2.3 fold 
increase in the annually integrated biomass (Table 2) and a longer duration of $\mathrm{N}_{2}$ fixing cyanobacteria blooms in the Baltic Sea. In addition, our model results show that the corresponding nitrogen input due to $\mathrm{N}_{2}$-fixation is more than twice as high. This would cause a change in biogeochemical cycling. Using the original formulation of cyanobacteria in the Baltic Sea ecosystem model in which the life cycle is ignored (Neumann 2000), the projection run indicates that the cyanobacteria concentrations are hardly changed compared to the hindcast period, despite an earlier start of the growth period (see Appendix B, Fig. 7).

Overall, our results with the life cycle model are consistent with a warming induced increase of cyanobacteria in the past years and the idea of a continuing trend in the future. The earlier start of the cyanobacteria bloom period in the projections is caused by the increase in air and thus sea surface temperature. Changes in wind speed have a rather minor impact on the cyanobacteria climatology, but may be significant in specific years.

The sensitivity experiments indicate that some mechanisms are amplified and some are damped in the projections. The succession of warm and cold years is more important in hindcast than in the projections. In contrast, the heating effect through light absorption and increase of cyanobacteria growth is more significant in the projections.

The model results further emphasize that the temperature sensitivity of cyanobacteria combined with their pronounced life cycle (growing pelagic and resting benthic stages) will make it next to impossible to predict interannual succession of blooms, even though the climatological state may be well represented. This means that projections cannot provide reliable information about outburst events of cyanobacteria, which are, however, from an ecological point of view of greater interest than the mean state.

Four additional aspects need to be considered in the interpretation of our results: First, global and regional climate projections are produced ignoring the feedback mechanisms of the ecosystem in general and cyanobacteria in particular. This may lead to systematic errors. For example, cyanobacteria feed back on the system not only via light absorption but also through changes in albedo and wind energy input (Sonntag and Hense 2011). Thus, the feedback of biotic processes on the system might be more important than usually assumed. Second, we have initialized our different model runs with the same initial conditions, including nutrients and standing stocks of akinetes. This was done to facilitate the comparison. However, the trend over the 70 years between the time slices (including anthropogenic nutrient discharges into the Baltic Sea) might lead to significantly different starting conditions. Third, we have ignored effects of global change due to ocean acidification. Enhanced growth and nitrogen fixation of open ocean cyanobacteria (Trichodesmium) under elevated $\mathrm{CO}_{2}$ concentrations has been observed (Levitan et al. 2007), so there might be an additional factor that contributes to higher and more widespread cyanobacteria blooms. Finally, we have assumed that there is no adaptation or interference with newly evolving or invading species or characteristics. So far, there is no generally accepted approach how to include evolutionary responses in ecosystem projections, which, however, does not imply that such processes might not happen.

Overall, we conclude that future projection studies aiming at the investigation of physical or biological changes in regions where cyanobacteria regularly occur need to include an adequate representation of the life cycle of these organisms (at least in 
a simplified way as suggested by Hense and Beckmann 2010) and biological-physical feedback mechanisms (as pointed out by Sonntag and Hense 2011).

Acknowledgements IH is grateful to Aike Beckmann for his critical comments on this study. Thanks go to Athanasia Nikolaou for preparing the forcing data sets used in this study and Irene Stemmler for valuable comments on the manuscript. The comments of two anonymous reviewers and the Editor are acknowledged. IH and SS were supported through the Cluster of Excellence 'CliSAP' (EXC177), University of Hamburg, funded through the German Science Foundation (DFG). MM's work is part of the project ECOSUPPORT and has received funding from the European Community's Seventh Framework Program (FTP/2007-2013) under grant agreement 217246 made with the BONUS program and from the Swedish Environmental Protection Agency $(08 / 381)$.

Open Access This article is distributed under the terms of the Creative Commons Attribution License which permits any use, distribution, and reproduction in any medium, provided the original author(s) and the source are credited.

\section{Appendix A: Statistical analyses of atmospheric variables}

We have analyzed the output of the regional climate model RCAO (which in turn uses the output of the GCM HadCM3 as lateral boundaries, see Fig. 6). The mean,

Fig. 6 Schematic overview of the models (rectangles) and data sets (ovals) involved in generating the final forcing fields to perform the model runs ERA40 (hindcast) and PROJ (projection). The model system used in this study is indicated by the shaded boxes

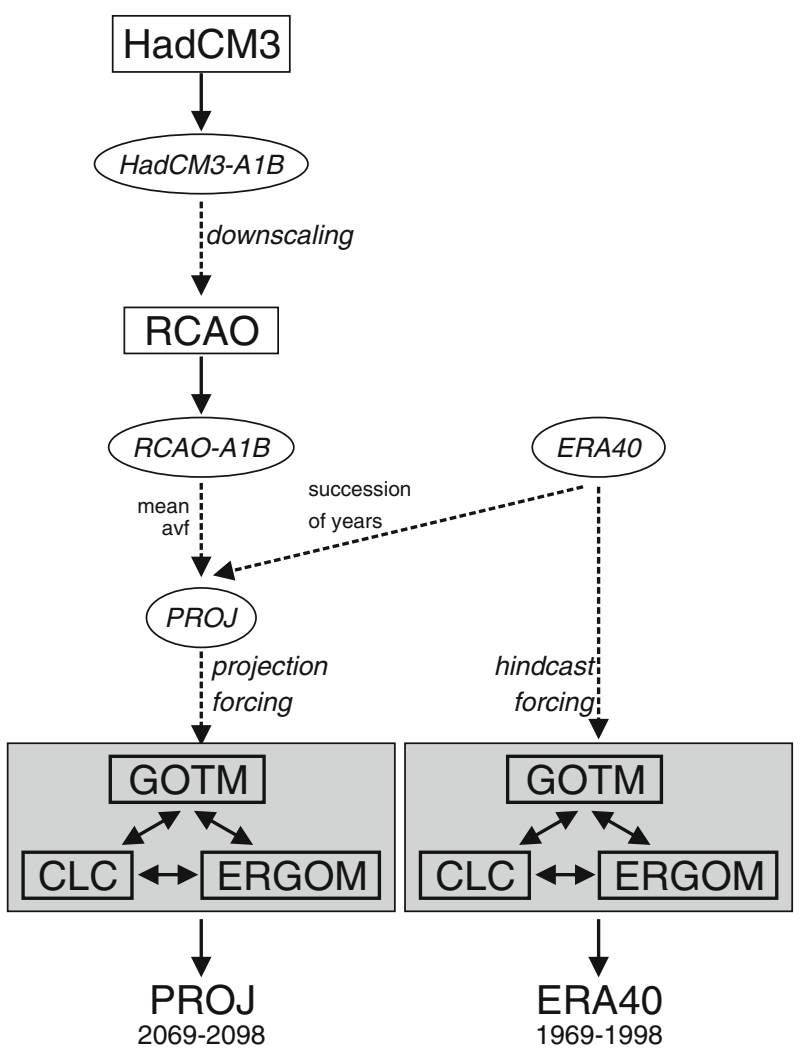


Table 3 Statistical analyses of the atmospheric variables at $57.3^{\circ} \mathrm{N}, 20^{\circ} \mathrm{E}$

\begin{tabular}{|c|c|c|c|c|c|c|}
\hline & $\begin{array}{l}\text { Wind speed } \\
\left(\mathrm{m} \mathrm{s}^{-1}\right)(10 \mathrm{~m})\end{array}$ & $\begin{array}{l}\text { Temperature } \\
\left({ }^{\circ} \mathrm{C}\right)(2 \mathrm{~m})\end{array}$ & $\begin{array}{l}\text { Dew point } \mathrm{T} \\
\left({ }^{\circ} \mathrm{C}\right)(2 \mathrm{~m})\end{array}$ & $\begin{array}{l}\text { Air pressure } \\
(\mathrm{hPa})(2 \mathrm{~m})\end{array}$ & $\begin{array}{l}\text { Cloud } \\
\text { cover - }\end{array}$ & $\begin{array}{l}\text { Precipitation } \\
\left(10^{-8}\right) \mathrm{m} \mathrm{s}^{-1}\end{array}$ \\
\hline \multicolumn{7}{|c|}{ ERA40 (1969-1998) } \\
\hline mean & 6.76 & 7.31 & 4.38 & $1,013.4$ & 0.646 & 1.88 \\
\hline stdev & 3.22 & 6.76 & 6.66 & 11.3 & 0.326 & 3.8 \\
\hline avf & 2.61 & 3.52 & 3.62 & 7.1 & 0.163 & 3.04 \\
\hline trend/30 yrs & -0.077 & 1.214 & 0.761 & -0.60 & -0.080 & -0.143 \\
\hline \multicolumn{7}{|c|}{ RCAO_HADCM20 (1969-1998) } \\
\hline mean & 7.21 & 7.66 & 4.56 & $1,011.2$ & 0.629 & 2.14 \\
\hline stdev & 3.48 & 6.92 & 7.30 & 10.4 & 0.338 & 5.94 \\
\hline avf & 2.82 & 3.59 & 4.04 & 6.4 & 0.163 & 5.16 \\
\hline trend/30 yrs & -0.159 & 0.078 & 0.152 & 1.15 & 0.006 & 0.091 \\
\hline \multicolumn{7}{|c|}{ RCAO_HADCM21 (2069-2098) } \\
\hline mean & 6.98 & 11.04 & 8.01 & $1,011.1$ & 0.632 & 2.57 \\
\hline stdev & 3.45 & 6.65 & 7.08 & 10.5 & 0.328 & 8.16 \\
\hline avf & 2.78 & 3.25 & 3.83 & 6.5 & 0.161 & 7.34 \\
\hline trend $/ 30 \mathrm{yrs}$ & -0.164 & 1.014 & 1.269 & -0.57 & -0.012 & 0.246 \\
\hline
\end{tabular}

standard deviation, absolute value of the fluctuations and the trend is shown for all atmospheric variables at $57.3^{\circ} \mathrm{N}, 20^{\circ} \mathrm{E}$ (Table 3 ).

\section{Appendix B: Additional sensitivity experiments}

We have conducted two additional experiments for the ERA40 (ERGOM-ERA40) and projection (ERGOM-PROJ) time period where we use the original model formulation for describing growth of cyanobacteria as in Neumann (2000). The life cycle is thus not included, leading to deficiencies in the climatological seasonal cycle and interannual variability in hindcast as pointed out by Hense and Burchard (2010). Similar to PROJ, we find an earlier start of the bloom in ERGOM-PROJ compared to the hindcast period (ERGOM-ERA40). However, the magnitude of the bloom remains almost the same (Fig. 7). The differences in the different model

Fig. 7 Climatological seasonal cycle of surface cyanobacteria concentrations in the hindcast and projection period in the model run including the life cycle (ERA40, PROJ) and in the model run with the original ERGOM cyanobacteria model (ERGOM-ERA40, ERGOM-PROJ) formulation, see Neumann (2000) and Hense and Burchard (2010)

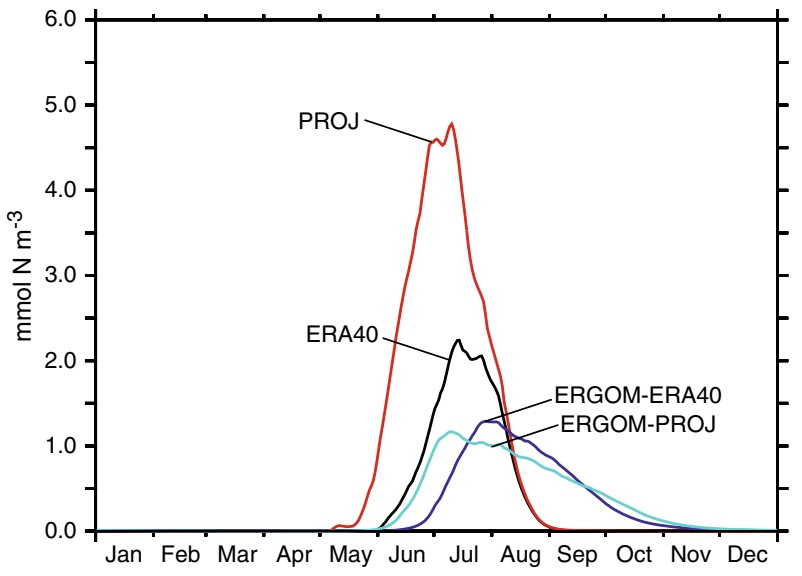


responses can be explained mainly by two model assumptions in ERGOM: First, it is assumed that the concentrations before the bloom period (inoculum) each year are identical (and also identical in hindcast and projections through the minimum value). Second, enhanced stratification reduces the flux of phosphate into the mixed layer and therefore limits the growth of cyanobacteria. Both aspects are different in our model formulation. Resolving the life cycle allows variability in the seed population. Additionally, we implicitly assume that the phosphorus demand is covered through uptake of dissolved organic phosphorus and phosphorus storage (Huber and Hamel 1985; Vahtera et al. 2007).

\section{References}

Boyd PW, Doney SC (2002) Modelling regional responses by marine pelagic ecosystems to global climate change. Geophys Res Lett 29:1806. doi:10.1029/2001GL014130

Döscher R, Willén U, Jones C, Rutgersson A, Meier HEM, Hansson U, Graham LP (2002) The development of the regional coupled ocean-atmosphere model RCAO. Boreal Environ Res 7:183-192

Elliott JA (2012) Is the future blue-green? A review of the current model predictions of how climate change could affect pelagic freshwater cyanobacteria. Water Res 46:1364-1371

Gordon C, Cooper C, Senior CA, Banks H, Gregory JM, Johns TC, Mitchell JFB, Wood RA (2000) The simulation of SST, sea ice extent and ocean heat transports in a version of the Hadley Centre coupled model without flux adjustments. Clim Dyn 16:147-168

Hense I (2007) Regulative feedback mechanisms in cyanobacteria-driven systems: a model study. Mar Ecol Prog Ser 339:41-47

Hense I, Beckmann A (2006) Towards a model of cyanobacteria life cycle—effects of growing and resting stages on bloom formation of $\mathrm{N}_{2}$-fixing species. Ecol Model 195:205-218

Hense I, Beckmann A (2010) The representation of cyanobacteria life cycle processes in aquatic ecosystem models. Ecol Model 221:2330-2338

Hense I, Burchard H (2010) Modelling cyanobacteria in shallow coastal seas. Ecol Model 221:238244

Huber AL, Hamel KS (1985) Phosphatase activities in relation to phosphorus nutrition in Nodularia spumigena (Cyanobacteriaceae). Hydrobiologia 123:145-152

Johnk KD, Huisman J, Sharples J, Sommeijer B, Visser PM, Stroom JM (2008) Summer heatwaves promote blooms of harmful cyanobacteria. Global Chang Biol 14:495-512

Kahru M, Leppaenen JM, Rud O (1993) Cyanobacterial blooms cause heating of the sea surface. Mar Ecol Prog Ser 101:1-7

Kahru M, Horstmann U, Rud O (1994) Satellite detection of increased cyanobacteria blooms in the Baltic Sea: natural fluctuation or ecosystem change? Ambio 23:469-472

Kahru M, Savchuk OP, Elmgren R (2007) Satellite measurements of cyanobacterial bloom frequency in the Baltic Sea: interannual and spatial variability. Mar Ecol Prog Ser 343:15-23

Karl D, Letelier R, Tupas L, Dore J, Christian J, Hebel D (1997) The role of nitrogen fixation in biogeochemical cycling in the subtropical North Pacific Ocean. Nature 388:533-538

Kosten S, Huszar VLM, Bécares E, Costa LS, van Donk E, Hansson LA, Jeppesen E, Kruk C, Lacerot G, Mazzeo N, Meester LD, Moss B, Lürling M, Nõges T, Romo S, Scheffer M (2011) Warmer climates boost cyanobacterial dominance in shallow lakes. Global Chang Biol 18:118126

Levitan O, Rosenberg G, Setlik I, Setlikova E, Grigel J, Klepetar J, Prasil O, Berman-Frank I (2007) Elevated CO2 enhances nitrogen fixation and growth in the marine cyanobacterium Trichodesmium. Global Chang Biol 13:531-538

Meier HEM, Höglund A, Döscher R, Andersson H, Löptien U, Kjellström E (2011a) Quality assessment of atmospheric surface fields over the Baltic Sea of an ensemble of regional climate model simulations with respect to ocean dynamics. Oceanologia 53:193-227

Meier HEM, Eilola K, Almroth E (2011b) Climate-related changes in marine ecosystems simulated with a three-dimensional coupled biogeochemical-physical model of the Baltic Sea. Clim Res 48:31-55 
Meier HEM, Andersson HC, Eilola K, Gustafsson B, Kuznetsov I, Müller-Karulis B, Neumann T, Savchuk OP (2011c) Hypoxia in future climates-a model ensemble study for the Baltic Sea. Geophys Res Lett 38:L24608. doi:10.1029/2011GL049929

Neumann T (2000) Towards a 3d-ecosystem model of the Baltic Sea. J Mar Syst 25:405-419

Neumann T (2010) Climate-change effects on the Baltic Sea ecosystem: a model study. J Mar Syst $81: 213-224$

Paerl HW, Huisman J (2008) Blooms like it hot. Science 320:57-58

Paerl HW, Huisman J (2009) Climate change: a catalyst for global expansion of harmful cyanobacterial blooms. Environ Microbiol Rep 1:27-37

Robarts RD, Zohary T (1987) Temperature effects on photosynthetic capacity, respiration, and growth rates of bloom-forming cyanobacteria. NZ J Mar Freshw Res 21:391-399

Rolff C, Almesjö L, Elmgren R (2007) Nitrogen fixation and abundance of the diazotrophic cyanobacterium Aphanizomenon sp. in the Baltic Proper. Mar Ecol Prog Ser 332:107-118

Sonntag S, Hense I (2011) Phytoplankton behavior affects ocean mixed layer dynamics through biological-physical feedback mechanisms. Geophys Res Lett 38:L15610. doi:10.1029/2011GL048205

Suikkanen S, Laamanen M, Huttunen M (2007) Long-term changes in summer phytoplankton communities of the open northern Baltic Sea. Estuar Coast Shelf Sci 71:580-592

Suikkanen S, Laamanen M, Huttunen M (2010) Life cycle strategies of bloom-forming, filamentous cyanobacteria in the Baltic Sea. Deep-Sea Res Part II 57:199-209

Umlauf L, Bolding K, Burchard H (2005) GOTM—scientific documentation. Version 3.2. In: Marine science reports, vol 63. Baltic Sea Research Institute, Warnemünde, Germany, 231 pp

Uppala S, Kallberg P, Simmons A, Andrae U, da Costa Bechtold V, Fiorino M, Gibson J, Haseler J, Hernandez A, Kelly G, Li X, Onogi K, Saarinen S, Sokka N, Allan R, Andersson E, Arpe K, Balmaseda M, Beljaars A, van de Berg L, Bidlot J, Bormann N, Caires S, Chevallier F, Dethof A, Dragosavac M, Fisher M, Fuentes M, Hagemann S, Holm E, Hoskins B, Isaksen L, Janssen P, Jenne R, McNally A, Mahfouf JF, Morcrette JJ, Rayner N, Saunders R, Simon P, Sterl A, Trenberth K, Untch A, Vasiljevic D, Viterbo P, Woollen J (2005) The ERA-40 re-analysis. Q J R Meteorol Soc 131:2961-3012

Vahtera E, Laamanen M, Rintala JM (2007) Use of different phosphorus sources by the bloomforming cyanobacteria Aphanizomenon flos-aquae and Nodularia spumigena. Aquat Microb Ecol 46:225-237

Wagner C, Adrian R (2004) Cyanobacteria dominance: quantifying the effects of climate change. Limnnol Oceanogr 54:2460-2468

Wiedner C, Rücker J, Brüggemann R, Nixdorf BS (2007) Climate change affects timing and size of populations of an invasive cyanobacterium in temperate regions. Oecologia 152:473-484 